ARTICLE

Received 17 Apr 2017 | Accepted 14 Aug 2017 | Published 12 Sep 2017

DOI: $10.1057 /$ palcomms.2017.93

OPEN

\title{
Storytelling and evidence-based policy: lessons from the grey literature
}

\author{
Brett Davidson ${ }^{1}$
}

ABSTRACT A number of authors interested in how to translate evidence into policy identify the importance of policy narrative and argue that advocates of scientific evidence need to tell good stories to grab the attention and appeal to the emotions of policymakers. Yet, this general call for better narratives is incomplete without concrete examples and evidence of their effectiveness. This article shows how these processes are described in the "grey" literature-defined as literature which is produced by all levels of government, academics, business and industry, but which is not controlled by commercial publishers. This literature is often missed by scientists but more important to activists and advocates within social movements and the non-profit sector who frequently engage with or seek to influence policymakers. The article outlines some of the ways in which an understanding of policymaker psychology and factors such as group dynamics and political context are reflected in the grey literature, and the implications of this for understanding the role of storytelling in political advocacy. It highlights practical advice about storytelling that emerges from the literature, and presents four case studies illustrating aspects of storytelling in action. It concludes by identifying the implications for scientists and other advocates of "evidence informed policymaking", practitioners and policymakers.

\footnotetext{
${ }^{1}$ Open Society Foundations Public Health Program, New York City, New York, USA Correspondence: (e-mail: brettdavi@gmail.com)
} 
For people who want the truth adequate evidence is enough but for those who don't want the truth overwhelming evidence is inadequate.-Tweet by Advocate Thuli Madonsela, former Public Protector of South Africa 4 July 2017

\section{Introduction}

- o ensure research findings are taken up into policy, scientists and social researchers need a more sophisticated understanding of policymaker psychology and the role of factors such as group dynamics and the rules that people follow within organizations. This is the view of Cairney and Kwiatkowski (2017), who examine some relevant insights provided by the fields of policy studies and psychology. However, they lament the fact that while many policy studies take into account how and why people make decisions, individually and within the complex systems of government, few go a step further to offer advice on how those who wish to influence policy should act in the light of these findings.

The communication scholar Walter Fisher (1984) and psychologist Jerome Bruner (1991) have argued that narrative is a key means through which people organize and make sense of reality and engage in reasoned argument-particularly when it comes to debating questions of values. More recently, scholars have focused on the importance of storytelling and narrative in policy and politics (see, for example, Polletta, 2006; and McBeth et al., 2014).

While Cairney and Kwiatkowski may lament the absence of advice within academia on how to make use of the insights such scholars have offered, there is in fact a large body of grey literature that does focus on providing practical guidance for those seeking to ensure uptake of evidence into policy. This literature draws on a range of insights from the world of academia, but also from practical lessons gained from years of trial and error within the field of policy advocacy.

In this paper I will outline some of the ways in which an understanding of policymaker psychology and factors such as group dynamics and political context are reflected in the grey literature, and the implications of this for understanding the role of storytelling in political advocacy. I will then highlight some of the key advice about storytelling that emerges from the literature, and point to a few of the resources that are available to scientists or other academic researchers seeking to influence policy. Finally, I present several case studies that illustrate aspects of storytelling in action.

\section{Defining grey literature}

The Grey Literature Report defines grey literature as literature which is produced by all levels of government, academics, business and industry, but which is not controlled by commercial publishers (Grey Literature Report n.d.). It includes reports, theses, conference proceedings, and official documents not published commercially.

The potential range of grey literature that could have been consulted for the purposes of this paper is vast. Among others, I made use of reports and publications produced by international organizations, NGOs, think tanks, foundations, consultancy organizations and individual experts working primarily in fields such as international development, human rights, and political and policy advocacy-some specifically focused on research uptake. Some sources are hybrids-organizations and experts who also publish in peer reviewed journals, or non-peer reviewed resources produced by university-based or independent research centres. As a grantmaker at the Open Society Public Health Program concerned with learning how best to support colleagues and grantees in advancing evidence-based policy, my primary interest has been in identifying publications that offer information I and others can put to use. Thus for the purposes of this article, I began with organizations and sources familiar to me from my own work in the field or recommended to me by respected colleagues, and branched out to additional resources referenced and referred to in the initial group. This cannot claim to be a comprehensive survey but is intended to present a sample of some of the rich resources that are available.

The resources I gathered seemed to fall into two main groups. The first grouping, mostly concerned with evidence informed policy in the global North, focuses on cognitive and psychological factors impacting the way in which individual policymakers make decisions (see for example Baron, 2010 and Bales, 2015a). These resources draw on recent research in fields such as cognitive science and neuropsychology, and explicitly make a link between such research and the ways in which stories take advantage of what we know about human decision-making. The second group, focused largely on evidence-based policy in the context of international development, tends to pay more attention to the political and organizational context and group dynamics within which policy processes take place, and the institutional processes by which decisions are reached (see for example, see Smutylo, 2005; Young and Mendizabal, 2009; and Young et al., 2014).

\section{Why storytelling is important}

The most basic definition of story is that "one thing happens in consequence of another" (Frank, 2010: 25). Story consists of a collection or body of stories about characters joined in some common problem as fixers (heroes), causes (villains) or the harmed (victims) in a temporal trajectory (plot), leading towards resolution within a particular setting or context (Fisher, 1984; Frank, 2010; McBeth et al., 2014). Ganz sees a story as crafted of three elements: plot, character, and moral. The effect depends on the setting: who tells the story, who listens, where they are, why they are there, and when (Ganz, 2011). Taking a cue from Labov, Polletta defines a story as "an account of a sequence of events in the order in which they occurred so as to make a normative point" (Polletta, 2006).

It is useful to examine in a little more detail some of the arguments for why storytelling is a vital tool for those seeking to ensure uptake of evidence in policy, before turning to the practical advice on storytelling available within the grey literature (see, for example, Baron, 2010; Goodman, 2013; VanDeCarr, 2015; Hattaway Team, 2017).

Individual decision-making. A first broad grouping of grey literature sources focuses on cognitive and psychological factors impacting the way in which individual policymakers make decisions. These draw on recent findings in fields such as cognitive science, neuroscience, psychology, behavioral economics, and anthropology, and explicitly make a link between such research and its implications for messaging strategies.

The World Bank's World Development Report for 2015, titled Mind, Society and Behavior, summarises some of the recent research on the way in which psychological and social factors impact behavior. The report distills three key insights about human decision-making: that humans think automatically (so-called fast thinking as described by the likes of Kahneman 2011, and referenced by Cairney and Kwiatkowski, 2017), we think socially (influenced by social networks, social identities, and social norms), and we think with mental models (frames, narratives, or worldviews that affect what people perceive and how they interpret what they perceive). The implication of these insights is that it is simply naive to believe that it is sufficient to present people with "the 
facts," and assume that they will weigh these in a detached and rational manner and act accordingly. This view, the so-called "deficit-model" has indeed long been recognized as inadequate within the field of science communication (Lock, 2011).

A number of organizations or projects that support researchers and scientists in communicating with policymakers draw on the same insights and have come to similar conclusions: the way in which information is presented is crucial (Compass n.d.; DRUSSA n.d.; Hendricks, 2017). In the case of automatic or fast thinking, this means that information has to be packaged in a manner that takes into account people's inherent cognitive biases and ensures that the information is quickly and easily-and accurately-grasped (Bales, 2015b). When it comes to social influences on thinking and decision-making, communicators need to understand the way in which people operate and made decisions as self-identified members of particular groups or "tribes" (Grimm, 2016). Because people think by making use of mental models, evidence has to be packaged or "framed" in ways that connect with people's values and take account of the frames, worldviews or narratives in people's heads of how the world works.

There are many ways in which stories take advantage of what we know about how human decision-making operates (Gold, 2017; Campbell et al., 2017). Through the mechanism of plot, stories can help make causal relationships apparent, helping audiences process complex information even when they are engaging in fast thinking. Stories position their tellers and listeners within particular social contexts, thus influencing the social identities through which audiences receive and process the message (Frank, 2010; World Bank, 2015). Stories help people make sense of "the facts" by framing them within particular narratives about how the world works (Cook and Lewandowsky, 2012; Bales, 2015a; Bales, 2015b).

As story consultant Andy Goodman puts it, "each of us walks around with a bunch of stories in our heads about the way the world works. And whatever we confront, whatever facts are presented to us, whatever data we run into, we filter through these stories. And if the data agrees with our stories, we'll let it in and if it doesn't, we'll reject it. So, if you're trying to give people new information that they don't have, they've got to have a story in their head that will let that data in" (Goodman, 2016).

Decision-making process and context. There is a second large body of grey literature that focuses on how to ensure evidence informed policymaking, which originates in the field of international development. While it does acknowledge the importance of messaging and understanding the psychology of individual decision-makers, this body of literature focuses more on the complex organizational and political context of policymaking. See for example Young et al. (2014), Young and Mendizabal (2009), Smutylo (2005), DFID (2009), Carden (2009), Young and Quinn (2002), IDRC (n.d.) and Young and Quinn (2012).

Among a number of factors that impact policymakers are the need to make quick decisions, the fact that they have wide briefs and thus can deal with individual issues only fairly superficially, and the reality that policymakers' concepts of what constitutes good evidence differ markedly from those of researchers. While researchers must be certain their findings are proven scientifically and theoretically sound (and even then they tend to qualify any conclusions with a range of caveats), policymakers look for anything that "seems reasonable, has a clear message and is available at the right time" (Davies, 2005 in Young and Mendizabal, 2009).

According to Young, et al. (2014), there is a range of ways in which policymakers can be influenced. Interventions can take place on an "Inside Track" or an "Outside Track", and within each of these "tracks", can take place formally or informally.

The inside track entails more cooperative relationships between scientific researchers, their allies, and policymakers, where engagement takes place directly through meetings, negotiations, and in-person discussions. On the formal level this takes the form of advising; on the informal level, it is known as lobbying. The concept of "knowledge brokering" is central to the inside track. Here it is necessary to inform and translate ${ }^{1}$ : conveying the data in a coherent way to help policymakers make sense of the research, but also showing why the research is important and how the proposed solutions are reasonable and make sense (Carden, 2009; Shaxson and Cassidy, 2013; Young et al., 2014).

The outside track tends to be more confrontational and often entails influencing decision-makers indirectly through public pressure. The more formal element of this is advocacy (for example through formal petitions), while activism is the informal aspect (for example direct action, à la Greenpeace). The outside track thus often means engaging in public campaigning and messaging, including through the mass media, to build public awareness of and support for an issue and thus public pressure for particular policies.

Looking at the organizational and contextual factors related to evidence- informed policy outlined above, stories can play an important role in a number of contexts. When the so-called "inside track" of influencing policy is followed-where policymakers are already interested in what researchers have to saystories are effective ways of summarizing key issues and concepts simply, quickly and effectively. At the same time, they are also able to appeal directly to policymakers' values and interests through their emotional content. In the case of the outside, more confrontational track, there is a need to build popular interest and support. In this case, stories are an important campaigning tool since they are key in mobilizing large numbers of people behind an issue (Da Costa, 2014) and encouraging them to take action that places pressure on the decisionmakers. Here, Ganz's (2011) model of public narrative is particularly relevant.

Questions about the concept of “evidence". Policy scholars bemoan "the irrationality of policymakers" in the academic literature (Cairney and Kwiatkowski, 2017). While acknowledging that moral and emotional factors often play a role in decisionmaking, this is seen as "suboptimal". The view seems to be that, ideally, scientists would present the "facts" or "evidence" to policymakers, who should then make purely rational choices. Having to tailor persuasive efforts towards the reality of emotional and moral decision-making is seen somehow as a corrupting factor, forcing scientists to reluctantly have to dirty their hands by tailoring their messaging in order to have influence over policy.

This view is problematic, however, as a number of authors within both the academic and grey literature point out. For example, Marcus (2010) draws on insights from neuroscience to argue that contrary to the view that rationality is a superior means of thinking that is degraded by emotion, it is in fact emotion that makes reason possible in the first place, and that emotion has a centrally important place in politics and democratic life.

Young and Mendizabal (2009) insist that it is necessary for researchers to become policy entrepreneurs if they are to have the influence they seek, given that many policy processes are only weakly informed by research-based evidence. ${ }^{2}$ Furthermore, several authors problematize the very concept of "evidencebased policy" and question what the concept of "evidence" means.

Firstly, while there is recognition that evidence is important, since decisions should be based on accurate knowledge of the world, authors such as Du Toit (2012) and Davies (2005) point 
out that often the most important questions that need to be answered are not ones that can be answered simply by turning to research. Some of the most important policy debates, particularly in deeply divided, multicultural societies, involve decisions not only about means but also about ends. These are questions of what "ought to be"-questions of values, not facts. In a similar vein, Mendizabal believes that often the issue is not finding the right answer, but settling on what the right question is in the first place. $^{3}$ Taking a slightly different perspective, Melamed (Melamed et al., 2016) argues that there are two kinds of facts: policy facts, and political facts. Policy facts exist when a government has an objective to achieve and wants to know how best to do it. The assumption is that politicians care about the evidence and will pay attention to those who have it. In contrast, political facts change how people view the world and what they see as important. These facts are gathered with an explicitly political purpose-that is, in some way to shift power. While they are still facts, they primarily arouse an emotional rather than a rational response. For example, Melamed mentions the figures released by Oxfam showing that a handful of people control the world's wealth. Debates linked to political facts are primarily about values.

Secondly there is the question of whose knowledge is valued, and whose evidence counts: "Does the origin of the evidence matter for uptake? Is origin irrelevant as long as the evidence is robust and incontrovertible? Or is locally generated, locally owned evidence likely to be more acceptable to local policymakers?" (Da Costa, 2014). There is a good deal of critique in the field of international development of the idea that knowledge or evidence provided by scientific experts, often from outside the community, country or region being researched, is superior to local knowledge based in people's daily experience. While locally generated evidence may take the form of formal, scientific evidence, it may also be informal or anecdotal. It may be provided by people who enjoy low social status, or who are stigmatized and marginalized. Such evidence may be routinely ignored by policymakers or technical experts-but there are many, many examples of tragic and expensive policy failures resulting from the fact that such evidence was not taken seriously (for example, see Sainath, 2000).

Thirdly, leaving aside the question of a debate over ends-even when the decision is about means, there is not always a clear and obvious solution. As Mendizabal (2013) points out, research merely offers alternative courses of action, but does not tell us what to do. Thus, evidence cannot exist and be taken up into policy in a purely rational way. Decisions must be made, and decisions are always made within particular power relationships. Bearing this in mind, Bennett and Jessani (2011) critique the idea of evidence-based policy as it "overlooks or plays down the role of power, uncertainty and chance", and point out that "there will never be a generalizable evidence base on which managers and policymakers will be able to draw unambiguously and to universal agreement".

The process through which decisions are made is thus crucial. As Davies (2005) argues, in a democracy, "it is not enough for something simply to be the best option-people must reach agreement that it is the best option". In a democratic society, participants, whether citizens or policymakers, must deliberate over the best course of action. Weighing of evidence plays a role, but there is also (and rightly so) contestation over what the issues are that need to be addressed, and what the questions are that need to be answered in the first place. Davies (2005) cautions that if, in an "evidence-obsessed world", policymakers and citizens are able to avoid key questions of what "ought to be" and citizens are able to evade making the effort of being involved with the processes by which they can make their interests and demands known, democracy is endangered and morality is "condemned to exile". Or, to put it a bit more cynically, "Policymaking is about politics, and evidence is only one of many variables in playing politics" (Da Costa, 2014).

Stories are an important mode through which deliberations take place over "ends", as opposed to "means" (although even when the discussion has to do with "means", stories can highlight the alternative courses of action and what might happen under each). Fisher (1984) argues that purely rational discussion takes place only within particular fields of expertise, involving neutral weighing of technical evidence. In contrast, narrative is an important mode through which everyday argument takes place. This is particularly important when the debate is over values (ends) or what "ought to be"- what Fisher (1984) calls "public moral argument". This does not mean the choice between competing narratives is arbitrary, however. We assess competing narratives on the basis of "narrative necessity" (Bruner, 1991). Fisher explains this as resting on two criteria: narrative probability (whether a story is coherent) and narrative fidelity (does the story ring true to the other stories people know to be true in their lives).

It is important to state that stories are not a "golden bullet". Stories are not always appropriate and carry limitations and dangers as well as benefits (Polletta, 2006; Frank, 2010; Goodman, 2013). Many a bad policy has been created because decisionmakers were moved to take action by a powerful story which was completely unrepresentative of a larger reality. Frank (2010) points out that the very thing that makes stories powerful, their openness to multiple understandings, means that stories can "always be told to different effect" and "turn against those who conscripted them" (2010:37). For example, so-called Dreamersyoung undocumented migrants in the United States, told stories that depicted them as "innocent" and thus deserving of protections, because they were brought to the United States by their parents at a young age through no decision of their ownonly to find these stories were used as justification for arresting and deporting their parents, who by definition were then not "innocent".

The limitations and potential pitfalls do not mean that storytelling should be abandoned. Storytelling remains a crucial communications tool for researchers seeking uptake of their evidence into policy. It does, however, mean that storytelling needs to be approached strategically.

\section{Developing a strategy}

Storytelling does not happen in a vacuum. The audience, the organizational and the political context must all be taken into account. Before focusing on particular tactics, such as the use of storytelling, those seeking uptake of evidence into policy need to develop a communication strategy.

The grey literature offers a great deal of advice for developing a strategy-often in the form of practical toolkits. With some variations, most of this literature focuses on a similar group of factors or steps that must be considered as part of a strategic plan to ensure policy impact. These include:

- Identifying the policy issue;

- Identifying and mapping the audience;

- Selecting an appropriate messenger;

- Getting the timing right and understanding the rhythms of the policy process;

- Building relationships and networks, and mapping the broader political context;

- Developing a theory of change;

- Developing a communication strategy along with appropriate messages; 
- Developing a clear monitoring and evaluation strategy (Young and Quinn, 2002; Young and Mendizabal, 2009; Young et al., 2014; Tilley et al., 2017).

Some of the grey literature resources provide overarching advice related to these factors, and others zoom in onto particular elements, offering very detailed guidelines on factors such as mapping the political context, or writing a policy brief, for example (IDRC n.d.). Several detailed case studies also show how evidence-informed policymaking is impacted by the organizational and political context within specific government departments. Examples of these are Shaxson et al. (2016) and McCaughey and Bruning (2010).

Spitfire Strategies' "Smart Chart" (Spitfire Strategies, 2017), well known within the non-profit world, is a particularly useful online tool that takes policy advocates through a step-by-step process in planning their communication strategy, from identifying a policy objective to identifying the audience, tailoring a message and evaluating success. A more recent publication by the same organization, titled Mindful Messaging (Grimm, 2016), focuses on ways to better understand how audiences hear, process and respond to messages.

\section{Telling effective stories}

Once a strategy has been developed, the messaging can be worked on with a clear audience in mind. There are a number of excellent grey-literature resources on how to communicate evidence effectively, and specifically on how to tell stories. There are also a number of organizations that work to assist or train scientists or policy researchers in telling stories to have impact. ${ }^{4}$ This section provides a brief overview of some the practical storytelling advice that is available.

Storytelling goal. The goal of the storytelling will vary, depending on the strategic context. Is the aim to convey the importance of a particular course of action, or is it simply to get an issue onto the top of the political agenda so that it gets the attention it deserves? Is there a need to convey the complexity of a particular issue and persuade policymakers to consider a wider range of views and voices, or is there a need to narrow down and push for adoption of a particular policy solution?

VanDeCarr (2013) outlines several functions that he believes stories can fulfil, including organising (stories can help mobilize people around an issue), advocating (stories can act as powerful persuasive tools), and educating (stories can simply help people better understand an issue and enable informed dialogue). Through these functions stories can help bring about changes in attitudes, behaviour, culture and policy.

The Active Voice lab (2017) uses the metaphor of horticulture to provide a taxonomy of types of stories that apply to different sorts of situations and requirements: rakes, shovels, trowels, sprinklers, trellises and wheelbarrows. For example, "rake" stories "scratch the surface of an issue" to engage people from a range of backgrounds, while "shovels" are investigative stories that dig deep for the truth and expose alarming information. This taxonomy can potentially help communicators think through what they are trying to achieve, construct an appropriate story, and then evaluate whether it achieved what it set out to do.

Sometimes the most pressing need may be to debunk misleading information that is leading to misguided policy decisions. In The Debunking Handbook, Cook and Lewandowsky (2012) provide insight on the most effective way to debunk myths. The authors outline experimental evidence that shows that most debunking efforts backfire because audiences tend to remember the repeated myths rather than the corrections. They go on to outline three key elements of an effective debunking effort: the refutation should focus on key facts rather than the myths; any mention of myths should be preceded by explicit warnings to the reader that what they are about to read is false; and the refutation should provide a narrative explaining why the myth is wrong and why it was initially advanced (2012).

Story structure. According to Ganz (2011), the plot of an effective story is structured around the elements of challenge, choice, and outcome: a character is moving towards some sort of goal, but is faced with a challenge. To move forward the character must make a choice, which leads to an outcome. Ganz teaches a particular model of storytelling, which he calls "Public Narrative", that can be useful in "outside track" situations, where researchers or their allies must try to mobilize public opinion to support a particular course of action. Public Narrative entails telling the story of self, of us and of now. The "story of self" is the personal story of the narrator, which makes clear a personal connection to the issue. "Story of us" seeks to show the audience why they share common values and concerns related to the issue, and the "story of now" is a call to action. It highlights the urgency of the situation and calls on the audience members to take concrete next steps to bring about change.

VanDeCarr (2015) offers similar advice. His tips for constructing a good story include: establishing a protagonist (whether an individual or a community), identifying what the protagonist wants or needs and the obstacles in their way, distilling a turning point or moment of change, and wrapping up with an ending that points the audience in the desired direction. It is also important that the story highlights the stakes involved-what stands to be lost or won.

While the elements of protagonist, challenge, turning point and resolution are key elements of good stories, policy advocates seeking to bring about systemic change would be well advised to use these elements in order to construct thematic rather than episodic stories (Iyengar, 1990). Episodic stories focus on particular concrete instances, such as single events or individuals, while thematic stories examine general trends (Papacharissi and de Fatima Oliveira, 2008). Episodic stories tend to elicit individualistic attributions of responsibility and thus individualistic solutions. Thematic stories, on the other hand, elicit societal attributions of responsibility and thus systemic solutions (Iyengar, 1990). The dilemma for communicators interested in advancing a more systemic understanding of issues is that mass media, and especially television, are oriented to focus on particular events-and thus episodic stories tend to predominate. The Frameworks Institute provides detailed practical advice on effective ways to tell thematic stories both generally, and with reference to particular issues such as education and climate change (Frameworks Institute n.d., Frameworks Institute, 2016; VanDeCarr, 2015a).

A range of other organisations focus specifically on providing advice on story construction to scientists and other academic researchers. These include the International Center for Policy Advocacy (ICPA, 2017), Economic and Social Research Council (see for example their Impact Toolkit: ESRC, 2017), DRUSSA, and Compass (Compass n.d.). DRUSSA offers a comprehensive online guide for research communicators, particularly focused on Africa (DRUSSA n.d.). Compass, among other groups, makes use of a so-called "message box". This tool consists of a diagram or series of diagrams that guides researchers through a number of steps in order to help them to distil their messages for nonscientific audiences (Baron, 2010).

Reinsborough and Canning (2010) provide guidance on the use of story to frame issues where there is a need to counter strong 
existing cultural narratives that work against the desired change. They offer worksheets to help guide would-be storytellers in thinking through and identifying key elements of their stories such as conflict, characters, imagery and foreshadowing.

Impactful stories. In their popular book, Made to Stick, Heath and Heath (2008) highlight several elements of impactful or "sticky" messages: simplicity, unexpectedness, concreteness, credibility, and emotion. All of these are useful to bear in mind when constructing a story. Concrete, sensory details are extremely important (Narativ, 2017). Not only do such details make a story more memorable - they also add to its credibility and emotional impact. Effective stories should also convey cause and effect in "simple, human terms" (Hattaway Team, 2017).

Imagery and metaphor are vitally important. Metaphors should be chosen carefully, as they can exert a powerful influence on the ways in which audiences understand issues. Several organizations provide research briefs to help guide storytelling on current policy issues, such as education or climate change-including advice on appropriate metaphors, based on audience and message research they have done (As a start, see Bales et al., 2015 and PIRC, 2017). For example, Bales et al. (2015) outline ways in which the American public understands climate change, key gaps in the public's understanding, and ways in which communicators can tap into commonly-held values (such as the values of protection, responsible management, and interconnection). They suggest several explanatory metaphors that they have found to be useful in helping people understand the basic mechanisms of climate change, such as: talking about carbon dioxide as a "heat-trapping blanket", talking about "regular versus rampant" $\mathrm{CO} 2$, and talking about the ocean as "climate's heart"-comparing the role of the ocean in regulating the climate system to the role of the heart in regulating the body (2015: 13).

Dealing with numbers. The way in which numbers are handled within stories requires particular thought and attention. Baron (2010) provides useful tips on ways to talk about numbers that are easily grasped, memorable, and faithful to the data. For example she recommends that in communication with lay audiences, scientists should sum up and simplify, use frequencies instead of probabilities (such as "three in a thousand"), compare and contrast (explaining what a number means by putting it into context), and talk about magnitude rather than significance.

Bales (2015b) also offers several practical lessons on telling stories with numbers. Firstly, numbers should not be used only to highlight crises - they should also be used to tell stories that allow people to see possible solutions. Secondly, it is important to help people to grasp the significance of numbers by using metaphors or comparisons with familiar things. Thirdly, numbers should not be used only to describe a situation but also to show how it arose and how it might be dealt with-in other words, to tell causal stories. Bales calls these explanatory chains: "Explanatory Chains point the public to the surrounding context, how human decisions contribute to the problem, and the policy opportunities that exist to prevent or even solve the problem" (2015b: 3).

Visual storytelling. Several resources highlight the importance and effectiveness of visual storytelling (DRUSSA n.d.; Emerson, 2008; Cook and Lewandowsky, 2012; Resource Media, 2015; Resource Media, 2016). These include detailed guidance on use of photography, graphics and data visualisations. Resource Media's most recent publication offers tips for testing images and nuggets of advice based on their own field tests, such as:

- use images the audience can recognize as local;
- include elements that help viewers relate personally;

- avoid images that spark interests unrelated to the key ask;

- text can enhance an image's impact but the image comes first;

- juxtaposition can be powerful (Resource Media, 2016).

The Tactical Technology Collective's excellent book and free online resource, Visualising Information for Advocacy offers extensive advice, along with numerous illustrations, on visual storytelling and how to construct and make use of visual information in campaigns (Emerson, 2008).

\section{Case studies: storytelling in action}

A few case studies may be useful to illustrate some ways in which storytelling can be used to influence policy. These examples are drawn from work I am familiar with or have been involved in, in the field of public health. They were not necessarily chosen for their evidence of impact, but do highlight some of the varied goals of storytelling and the many ways in which storytelling can take place.

Stop Stockouts: visual storytelling to get media attention. For years, primary health care facilities in Africa have been plagued by a chronic and well-documented problem: low availability of essential medicines in public health facilities. When a pharmacy in a medical store or health facility temporarily runs out of medicine on the shelf, it is known as a "stock-out". Stock-outs force people to purchase medicines from the higher-priced private sector, or-more frequently-simply to go without needed medicines. As a result, they suffer from treatable conditions, often with life-and-death consequences.

Although Health Action International (HAI) Africa had documented year after year the chronic unavailability of essential medicines in Eastern and Southern Africa, they had been unable to turn the problem into questions of public debate and policy. Because much of the data were presented in a technical and complex form, it was difficult for activists to understand the issues or find ways to use them for advocacy. Despite a public campaign highlighting the problem, the media had largely remained uninterested, and governments either insisted that more research was needed, or that the issue had already been dealt with.

Eventually, in June 2009, HAI Africa and its partner organisations decided to stage a "pill check" week. This made use of text messaging and online mapping tools (Frontline SMS and Ushahidi), to enable members of the public to submit an instant report by SMS when they experienced stock outs of a particular essential medicine at their public health facility. In addition to calling for messages from members of the public impacted by stock-outs, campaign members in Kenya, Uganda, Malawi and Zambia also visited public health institutions to enquire about the availability of ten basic essential medicines that should be readily available in public health facilities. The results, reported via text message, were then used to populate an online map that highlighted areas where essential medicine stock-outs were experienced by patients in that week. Teams in each of the countries then held press conferences to present the findings.

The campaign attracted significant attention from national and regional journalists, and soon led to an opening up of the debate on stock-outs and a shift in the responses from governments. For example, in Kenya, the Ministry of Public Health and Sanitation had previously issued a press statement denying the very existence of stock-outs. However, following a press conference to disseminate the Pill Check Week findings, the Minister of Medical Services admitted that there were stock-outs in public 
health facilities in Kenya, and confirmed that extra funds would be used to purchase essential medicines. In Uganda, the Ministry of Health in Kampala acknowledged the drug shortages taking place in the country on prime-time TV news (Buissonniere, 2010).

The Pill Check Week was essentially a stunt rather than a research project, since while the reports of stock-outs were real ones, they did not provide a representative sample, nor were the reports rigorously verified. However, the stunt achieved an impact that years of painstakingly gathered, reliable research data had not. This is because it told several stories. The online map, with large clusters of red flags dotted around the participating countries, provided an immediate visual story of stock-outs that was dramatic and could not be denied or be said to be out of date.

Each flag represented a story of a real individual who had been unable to fill a prescription because of a stock-out in the previous 7 days. Then too, the creative use of the mobile phone technology and online mapping was a story in itself that in some cases was seen as more newsworthy -because it was so unusual-than the ongoing issue of medicine shortages.

This case is an example of the creation of an event that played into the media's preference for episodic storytelling-only to make use of the resulting media attention in order to tell a thematic story. The event also made effective use of visual storytelling to establish the credibility of evidence that policymakers had previously been able to dismiss as inadequate. The numbers conveyed were not precise measures of the extent of the problem, but the numbers in visual form (as red flags clustered on a map) effectively conveyed the widespread nature of the problem.

Here I Am Campaign: Giving statistics a human face. ${ }^{5}$ The Global Fund to Fight Aids, Tuberculosis and Malaria (Global Fund) was set up in 2002 as an international financing organization to attract and pool funds from donor nations, and disburse money to countries in need of expanding prevention and treatment of HIV and Aids, Tuberculosis and Malaria. The Global Fund was instrumental in significantly expanding treatment and this was well documented. However, following the 2008 financial crisis, media reports of misuse of funds in some African countries, and a leadership shake-up, several member countries cut their pledges to the fund, while others failed to meet prior commitments. It looked likely that donor commitments towards replenishment of the fund would not meet projected targets, and in November 2011 the Fund's board announced that it had cancelled the next round of grants for 2012 (Knox, 2011). As part of its efforts to advocate for full replenishment of the Fund, the Global Fund Advocates Network (GFAN) launched the Here I Am Campaign, which told the stories of individuals who were benefiting from treatment paid for by the Fund, and thus were alive and thriving (GFAN, 2017b). The rationale behind the campaign was that the statistics showing expansion in treatment roll-out internationally as a result of the Fund's disbursements would not be sufficient to persuade decision-makers to replenish the fund. In addition, those statistics were usually accompanied by figures showing how much more would still be neededpossibly leading to donor fatigue as a result of the view that despite the positive impact, money was pouring into a bottomless pit. The advocates felt it was crucial to present donor nations with examples of the real people who were alive thanks to the Fund, and that this would provide the emotional impact needed to convince key decision makers. They believed it would be easier to cut numbers on a page than to deny a specific individual the medicine she or he needed to survive. In 2012, the campaign gathered 198 short video testimonies from individuals around the world, and made these available online on the campaign website as well as on YouTube (GFAN, 2017a). Several of the most impactful videos were shown to decision-makers within the governments of donor nations in individual meetings, and following a request from the Fund, were also screened at the Fund's board meeting in 2012. At the Fund's replenishment meeting in December 2013, 25 countries pledged US $\$ 12$ billiona 30\% increase from pledges secured in the previous Global Fund Replenishment (Results, 2013).

It is impossible to know the extent to which the stories of the Here I Am Campaign contributed to this success, but from their individual interactions with decision-makers, the advocates believe that these stories made an important contribution. The Here I am Campaign is an example of storytelling that put a human face/s to anonymous statistics-in this case, with the aim of rewarding decision-makers for their financial support (by showing concrete examples of success) in order to encourage them to continue and renew their existing efforts. Each individual episodic story was placed within a thematic context through the use of graphics at the beginning and end of each video, while the large number of episodic stories from around the world, also served to tell a broader, thematic story.

Intersex Stories: Personal experience as evidence. Intersex people are born with a wide range of naturally occurring differences in their physical sex traits that make their bodies appear outside the binary medical categories of either male or female sex. Sex trait variances can include one or more of the following: genitals, internal reproductive organs, chromosomal patterns and hormone levels. Intersex people have a long history of being subjected to invasive and often irreversible medical interventions, and the US-based organization interACT advocates for laws and policies to protect children born with intersex traits. However, intersex people often struggle to have their voices heard, and allegations of human rights abuses of intersex people in medical settings are often ignored. Therefore, the organization jumped at the chance to have stories of intersex people featured in the academic journal, Narrative Inquiry in Bioethics. Not only did this provide a chance for intersex people to tell their stories, but the fact that they would appear in a respected journal, published by Johns Hopkins University Press, gave the stories a gravitas and credibility they would probably not otherwise have enjoyed. However, recognizing the journal reaches a very limited audience, interACT then sought and obtained a grant that enabled them to purchase the rights to the stories, which they republished in a format and layout that is more accessible and appealing to lay audiences. The publication, Normalizing Intersex is available free of charge as a PDF, no longer behind the journal's paywall ${ }^{6}$ (DuBois and Ilitis, 2016). interACT launched the publication at a major medical conference, where they also arranged author readings and panel discussions on the challenges, strategies and lessons learned from the stories. Flyers with the link to access the online edition were distributed to attendees along with hard copies. The organization continues to use the stories in its advocacy. It uses stories in other ways too. For example, when fashion model Hanne Gaby Odiele came out as intersex, interACT partnered with her to ensure that key advocacy messages were included in the ensuing publicity. This proved hugely successful, as Odiele's story was featured widely in outlets such as Vogue, the New York Times, and the BBC World Service (Interact Advocates, 2017).

This case illustrates the strategic choice of storytelling medium in order to give legitimacy to voices that are often ignored and help ensure that people's personal experience is taken seriously as evidence, by a skeptical audience. As with the previous example, it illustrates the use of a large number of episodic stories in order to convey a thematic, systemic story. 
Cops and Rubbers: storytelling as role-play. In 2012, the Open Society Public Health Program released a research report titled Criminalizing Condoms (Shields, 2012). This report outlined the way in which police in Kenya, Namibia, Russia, South Africa, the United States and Zimbabwe frequently search sex workers for condoms, arresting them and confiscating the condoms if found, and using the condoms as evidence in prosecution proceedings. In addition to releasing the written report, and to ensure a wider audience, the Open Society Foundations' media team produced a short video featuring the stories of several of the sex workers whose testimony was included in the report (Thomas, 2012). On top of that, in preparation for the 2012 International Aids Conference in Washington, DC, which would entail the presence of influential decision-makers in public health and widespread media attention, the OSF team worked with game designer Lien Tran, to produce a role-play board game, named Cops and Rubbers (Public Health Program, 2013). ${ }^{7}$ To play the game, participants have to take on an identity as a sex worker, and through six rounds of play try to achieve an income goal, while trying to stay out of jail and remain healthy by preventing the police from finding and taking their condoms. Game cards include instructions guiding play, as well as quotations from real sex workers, outlining their experiences. The game thus personalizes the issue and allows an opportunity for participants to discuss the matter in more detail with the facilitator and fellow participants. Research undertaken by Tran indicates that the game was useful in breaking barriers related to stigma and discrimination. It was not conclusive whether the report or the game was more effective in conveying information and understanding of the issue. Unlike the report, however, the game aroused a range of emotions in participants, including feelings of empathy (Tran and Mcfarlane, 2016).

This example shows the innovative use of storytelling in game form, in order to assist audience members to identify with the protagonists' plight (through role-play). The quotes used within the game include concrete, sense-based details that convey the characters' lived reality and carry a great deal of emotional power. Through the game play, players gain an understanding of the systemic nature of the problem (problematic laws), rather than being encouraged to attach blame to individual behavior. The game makes use of the key elements of story outlined earlier-the protagonists have a goal (to make $\mathrm{x}$ amount of money), face challenges and must make choices-but the outcomes turn out not to be the result of individual choices, but of a system that places obstacles in the way.

\section{Conclusion}

There is recognition within the academic literature focused on evidence-informed policy that scientists need a more sophisticated understanding of policymaker psychology and the role of factors such as group dynamics and the rules that people follow within organizations. There is also recognition that storytelling is an important messaging tactic that scientists need to learn to make use of in their communications strategies aimed at policymakers. In this article, I have attempted to show that there is a large body of grey literature from within the field of policy advocacy, that offers a great deal of practical, "how to" advice to researchers and scientists seeking to make use of the power of storytelling to influence policy.

While the academic world of policy studies seems unaware of this wealth of practical resources, the grey literature seems unaware of the value that policy studies can offer. While much of this literature seems to draw on the fields of development studies, psychology, cognitive science and communication, almost none of it that I could find drew on academic theories of policy processes. Sources that did reference a model of the "policy process" tended to rely on the outdated, simplistic, linear "policy cycle" model. This is unfortunate as policy advocates working within NGOs, foundations and think tanks could greatly benefit from the potential strategic insights to be gained from more widespread familiarity with a broad range of policy concepts.

$\mathrm{Be}$ that as it may. For a scientist or social researcher interested in exploring storytelling as a communication tool, many of the resources and toolkits mentioned in this paper offer a good place to start. For example, the Smart Chart (Spitfire Strategies, 2017) can be used as a first step, to flesh out a strategy. From there, The Message Box Workbook is helpful for distilling the essence of a message. The Frameworks Institute's resources offer guidance on how to structure a thematic story, as well as message research briefs on issues such as climate change, education and health. Resource Media and the Tactical Technology Collective offer excellent free toolkits and tutorials in visual storytelling.

However, these are just a few examples. I hope that this paper has served to highlight the wealth of resources that exists, and along with other papers in this series, will enable those interested to combine the insights available within the grey literature with those offered by more academic policy studies.

\section{Notes}

1 Young et al. (2014) propose that other elements of knowledge brokering are linking (connecting policymakers to known experts on particular issues) and matchmaking (introducing people to others they would usually not meet).

2 The concept of policy entrepreneurship refers to "the idea that researchers can move beyond simply producing and disseminating knowledge to directly engaging with policymakers from the earliest stages of research in order to influence their decisions" (Young et al., 2014).

3 Thus, storytelling is important not only in trying to persuade policy makers of a particular course of action but also in "agenda-setting"-persuading them of the importance of the issue over others competing for attention (Scheufele, 2000).

4 Examples include Compass (www.compassscicomm.org), the Alan Alda Center for Communicating Science (http://www.aldakavlilearningcenter.org/), Guerilla Science (http://guerillascience.org/), Storycollider (www.storycollider.org), Frameworks Institute (www.frameworksinstitute) to name a few.

5 Some of the stories can be viewed here: https://www.youtube.com/playlist?list $=\mathrm{PL}_{-}$ HsGl3DUrkbC7LnlrVAQXIMNPLDb_g8S

6 The publication can be viewed here:http://www.nibjournal.org/news/documents/Voi ces_2016_OA_FINAL-withOLOS_version_001.pdf

7 An online version of the game can be found here: http://copsandrubbers.com/

\section{References}

Active Voice Lab. (2017) Horticulture Tools-How Do We Know. Active Voice Lab, https://www.activevoice.net/how-do-we-know/home/horticulture-tools/, accessed 4 April 2017.

Bales SN (2015a) Disrupting the Dominant Frame: An Interview with Susan Nall Bales of the FrameWorks Institute, 2015 MACEI Award Winner - Non Profit News For Nonprofit Organizations. Nonprofit Quarterly, https://nonprofitquar terly.org/2015/02/05/disrupting-the-dominant-frame-an-interview-with-susannall-bales-of-the-frameworks-institute-2015-macei-award-winner/, accessed 24 March 2017.

Bales SN (2015b) The Storytelling Power of Numbers. Frameworks Institute: Washington DC.

Bales SN, Sweetland J and Volmert A (2015) How to Talk about Climate Change and the Ocean. Frameworks Institute: Washington, DC.

Baron N (2010) Escape From the Ivory Tower. Island Press: Washington DC, ISBN, 978, p.1597266635.

Bennett G and Jessani N (eds) (2011) Knowledge Translation Toolkit. Sage; IDRC: New Delhi, India.

Bruner J (1991) The narrative construction of reality. Critical Inquiry; 18 (1): 1-22.

Buissonniere M (2010) The stop stockouts campaign. In: HAI Africa Encyclopedia on the Politics of Medicine (2009-2010). HAI Africa: Nairobi, Kenya.

Cairney P and Kwiatkowski R (2017) What Can We Learn From Psychology About How Policymakers Think, Act, and Use Evidence?. Palgrave Macmillan, forthcoming.

Campbell T, Griffin L and Niemand A (2017) Persuasion in a "Post-Truth" World, https://ssir.org/articles/entry/persuasion_in_a_post_truth_world, accessed 13 April 2017. 
Carden F (2009) Knowledge to Policy. Sage; IDRC: New Delhi, India.

Compass, COMPASS: The Message Box Workbook. COMPASS( ${ }^{* * P l e a s e}$ reoreder it accordingly), https://www.compassscicomm.org/the-message-box-workbook, accessed 23 March 2017.

Cook J and Lewandowsky S (2012) The Debunking Handbook. University of Queensland: St Lucia, Australia.

Da Costa P (2014) "Research TO Policy?" Reflections on a Persistently Intriguing Debate, https://onthinktanks.org/articles/research-to-policy-reflections-on-apersistently-intriguing-debate/, accessed 31 March 2017.

Davies W (2005) Evidence-based policy and democracy. Open Democracy, https:// www.opendemocracy.net/democracy-think_tank/policy_3056.jsp, accessed 31 March 2017.

DFID. (2009) Political Economy Analysis How To Note, DFID, http://www.gsdrc. org/docs/open/po58.pdf.

DRUSSA. A Research Communicators' Guide for African Universities. Development Research Uptake in Sub-Saharan Africa-DRUSSA, http://researchcom municationguide.drussa.net/, accessed 31 March 2017.

DuBois JM and Ilitis AS (eds) (2016) Normalizing Intersex. Voices: Personal stories from the pages of NIB, http://www.nibjournal.org/news/documents/Voices_ 2016_OA_FINAL-withOLOS_version_001.pdf.

Du Toit A (2012) Making Sense of "Evidence": Notes on the Discursive Politics of Research and Pro-Poor Policy Making. PLAAS, UWC: Bellville, South Africa.

Emerson J (2008) Visualizing Information for Advocacy: Introduction to Information Design. Tactical Technology Collective: Bangalore.

ESRC. (2017) Impact toolkit-Economic and Social Research Council, http://www. esrc.ac.uk/research/impact-toolkit/, accessed 13 April 2017.

Fisher WR (1984) Narration as a human communication paradigm: The case of public moral argument. Communication Monographs; 51 (1): 1-22.

Frameworks Institute. Reframing Success Stories. Frameworks Institute, http://www. frameworksinstitute.org/assets/files/reframingsuccessstories.pdf, accessed 18 July 2017.

Frameworks Institute. (2016) Can your climate communications be Clearer and more effective? Try these tested tools, http://www.frameworksinstitute.org/ assets/files/climate/NNOCCI_flyer_02.pdf.

Frank AW (2010) Letting Stories Breathe: A Socio-Narratology. University of Chicago Press: Chicago.

Ganz M (2011) Public narrative, collective action, and power. In: Odugbemi S and Lee T (eds). Accountability through Public Opinion: From Inertia to Public Action. The World Bank: Washington DC, pp 273-289.

GFAN. (2017a) Global Fund Advocates Network: YouTube page. YouTube, https:// www.youtube.com/user/HereIAmCampaign, accessed 13 April 2017.

GFAN. (2017b) Here I Am Campaign. Global Fund Advocates Network, http:// www.globalfundadvocatesnetwork.org/campaign/here-i-am-campaign/, accessed 13 April 2017.

Gold D (2017) "Data-Driven" Campaigns Are Killing the Democratic Party. Politico, http://www.politico.com/magazine/story/2017/02/data-driven-cam paigns-democrats-need-message-214759, accessed 13 April 2017.

Goodman A (2016) If You're Going to Change the World, You Better Bring Your Stories: An Interview with Andy Goodman. Frank, http://frank.jou.ufl.edu/ 2016/09/change-stories/, accessed 23 March 2017.

Goodman A (2013) Storytelling as Best Practice, Sixth Edition, The Goodman Center: Los Angeles, CA.

Grey Literature Report. What is Grey Literature? Grey Literature Database, http:// www.greylit.org/about accessed 18 July 2017.

Grimm K (2016) Mindful Messaging. Spitfire. Available at, http://mindfulmessa ging.spitfirestrategies.com/wp-content/uploads/2016/11/Mindful-Messagingprint2.pdf.

Hattaway Team. (2017) The Science of Storytelling, Part 1: Help Your Audience Understand Cause and Effect, http://www.aspiration.al/science-of-storytellingpart-1-cause-and-effect/, accessed 13 April 2017.

Heath C and Heath D (2008) Made to Stick: Why Some Ideas Survive and Others Die. Random House Publishing Group: New York.

Hendricks R (2017) Communicating climate change: Focus on the framing, not just the facts. The Conversation, http://theconversation.com/communicating-cli mate-change-focus-on-the-framing-not-just-the-facts-73028, accessed 23 March 2017.

ICPA. (2017) Developing Practical Skills To Influence Decision-Making. International Center for Policy Advocacy, http://www.icpolicyadvocacy.org/, accessed 13 April 2017.

IDRC. How to Write a Policy Brief, IDRC, https://prd-idrc.azureedge.net/sites/ default/files/idrcpolicybrieftoolkit.pdf

Interact Advocates. (2017) Hanne Gaby Odiele is intersex! Interact advocates, http://interactadvocates.org/our-advocacy/intersex-media/hanne/, accessed 13 April 2017

Iyengar S (1990) Framing responsibility for political issues: The case of poverty. Political Behavior; 12 (1): 19-40.

Knox R (2011) Obama Embraces "End of AIDS," Promises To Accelerate HIV Treatment, http://www.npr.org/sections/health-shots/2011/12/01/143024108/ obama-embraces-end-of-aids-promises-to-accelerate-hiv-treatment, accessed 13 April 2017.

Lock SJ (2011) Deficits and dialogues: Science communication and the public understanding of science in the UK. In: Bennett DJ and Jennings RC (eds). Successful Science Communication. Cambridge University Press: Cambridge.

Marcus GE (2010) Sentimental Citizen: Emotion in Democratic Politics. Penn State Press: University Park.

McBeth MK, Jones MD and Shanahan EA (2014) The narrative policy framework. In: Sabatier PA and Weible CM (eds). Theories of the Policy Process. Avalon Publishing: Boulder, CO.

McCaughey D and Bruning NS (2010) Rationality versus reality: The challenges of evidence-based decision making for health policy makers. Implementation Science: IS; $\mathbf{5},(39)$.

Melamed C, Shaxson L and Young J (2016) Brexit, Chilcot and evidence-based decision making. ODI, https://www.odi.org/comment/10425-brexit-chilcotand-evidence-based-decision-making. accessed 10 August 2017.

Mendizabal E (2013) Research uptake: what is it and can it be measured? On Think Tanks, https://onthinktanks.org/articles/research-uptake-what-is-it-and-can-itbe-measured/, accessed 31 March 2017.

Narativ. (2017) Narativ, http://narativ.com/, accessed 13 April 2017.

Papacharissi Z and de Fatima Oliveira M (2008) News frames terrorism: A comparative analysis of frames employed in terrorism coverage in US and UK newspapers. The International Journal of Press/Politics; 13 (1): 52-74.

Polletta F (2006) It Was Like a Fever: Storytelling in Protest and Politics. University of Chicago Press: Chicago.

PIRC. (2017) Public Interest Research Centre. PIRC, http://publicinterest.org.uk/ downloads, accessed 18 July 2017.

Public Health Program. (2013) Cops \& Rubbers: An Interactive Game About Sex Work and Policing. Open Society Foundations, https://www.opensocietyfounda tions.org/publications/cops-rubbers, accessed 13 April 2017.

Reinsborough P and Canning D (2010) RE:Imagining Change: How to Use Storybased Strategy to Win Campaigns, Build Movements, and Change the World. PM Press: Oakland, CA.

Resource Media. (2015) Seeing is Believing: A guide to visual storytelling best practices, Resource Media, http://www.resource-media.org/seeing-is-believingreport/.

Resource Media. (2016) What They See Matters: Visual communication takeaways from audience research and tips for testing images, Resource Media, http://www. resource-media.org/wp-content/uploads/2016/03/What-They-See-MattersImage-Testing-Guide.pdf.

Results. (2013) Historic Replenishment of the Global Fund to Fight AIDS, TB and Malaria Only a Starting Point. RESULTS UK, http://www.results.org.uk/blog/ historic-replenishment-global-fund-fight-aids-tb-and-malaria-only-startingpoint, accessed 13 April 2017.

Sainath P (2000) Everybody Loves a Good Drought. Penguin: New Delhi.

Scheufele D (2000) Agenda setting, priming, and framing revisited: Another look at cognitive effects of political communication. Mass Communication \& Society; 3 (2-3): 297-316.

Shaxson L, Datta A, Tshangela M and Matomela B (2016) Understanding the Organisational Context for Evidence-Informed Policy-Making. Overseas Development Institute: Pretoria, South Africa, London.

Shaxson L and Cassidy C (2013) Impact and Communications Strategy: Supporting projects to achieve impact, DFID, ESRC and ODI, https://static1.squarespace. com/static/5167f6a2e4b0f1cbdee8d1c0/t/5239a82ae4b0a981d2a07897/ 1379510314660/DEGRP+Impact+and+Communications+Strategy+September +2013.pdf.

Shields A (2012) Criminalizing Condoms, Open Society Foundations, https://www. opensocietyfoundations.org/sites/default/files/criminalizing-condoms20120717.pdf.

Smutylo T (2005) Outcome mapping: A method for tracking behavioural changes in development programs, Institutional Learning and Change Initiative (ILAC), http://www.outcomemapping.ca/download/csette_en_ILAC_Brief07_mapping. pdf.

Spitfire Strategies. (2017) Smart Chart. Smart Chart, http://smartchart.org/, accessed 13 April 2017.

Thomas R (2012) Why Do They Take Our Condoms, Do They Want Us to Die? Open Society Foundations, https://www.opensocietyfoundations.org/ voices/why-do-they-take-our-condoms-do-they-want-us-die, accessed 13 April 2017.

Tilley H, Shaxson L, Young J, Rea J and Ball L (2017) Things To Know About How To Influence Policy With Research. Overseas Development Institute: London.

Tran L and Mcfarlane SJ (2016) An Evaluation of Games for Advocacy: A Qualitative Research Study Conducted in Cape Town, South Africa. University of Miami: Miami.

VanDeCarr P (2013) Storytelling and Social Change: A Strategy Guide for Grantmakers. Working Narratives: New York.

VanDeCarr P (2015) Storytelling and Social Change: A Strategy Guide. Working Narratives, http://workingnarratives.org/story-guide/, accessed 13 April 2017. 
VanDeCarr P (2015a) 3 Tips for Telling Stories That Move People to Action. The Chronicle of Philanthropy, https://www.philanthropy.com/article/3-Tips-forTelling-Stories/228559, accessed 18 July 2017.

World_Bank. (2015) Mind, Society and Behavior: World Development Report 2015, World Bank, http://dx.doi.org/10.1596/978-1-4648-0342-0.

Young E and Quinn L (2012) Making Research Evidence Matter: A Guide to Policy Advocacy in Transition Countries. Open Society Foundations: Budapest.

Young E and Quinn L (2002) Writing Effective Public Policy Papers: A Guide for Policy Advisers in Central and Eastern Europe. Open Society Institute: Budapest.

Young J, Shaxson L, Jones H, Hearn S, Datta A and Cassidy C (2014) ROMA: A Guide to Policy Engagement and Influence. Overseas Development Institute (ODI): London.

Young J and Mendizabal E (2009) Helping Researchers Become Policy Entrepreneurs: How to Develop Engagement Strategies for Evidence-Based Policy-Making. Overseas Development Institute (ODI): London.

\section{Data availability}

Data sharing is not applicable to this article as no datasets were generated or analysed during the current study.

\section{Acknowledgements}

The author thanks the anonymous reviewers, Paul Cairney, Linda Cilliers and Mark Rosin, for their helpful comments and suggestions on earlier drafts of this article.

\section{Additional information}

Competing interests: The author declares that there are no competing financial interests.

Reprints and permission information is available at http://www.palgrave-journals.com/ pal/authors/rights_and_permissions.html

How to cite this article: Davidson B (2017) Storytelling and evidence-based policy: lessons from the grey literature. Palgrave Communications. 3:17093 doi: 10.1057/ palcomms.2017.93.

Publisher's note: Springer Nature remains neutral with regard to jurisdictional claims in published maps and institutional affiliations.

\section{(c) (i)}

This work is licensed under a Creative Commons Attribution 4.0 International License. The images or other third party material in this article are included in the article's Creative Commons license, unless indicated otherwise in the credit line; if the material is not included under the Creative Commons license, users will need to obtain permission from the license holder to reproduce the material. To view a copy of this license, visit http://creativecommons.org/licenses/by/4.0/

(C) The Author(s) 2017 